
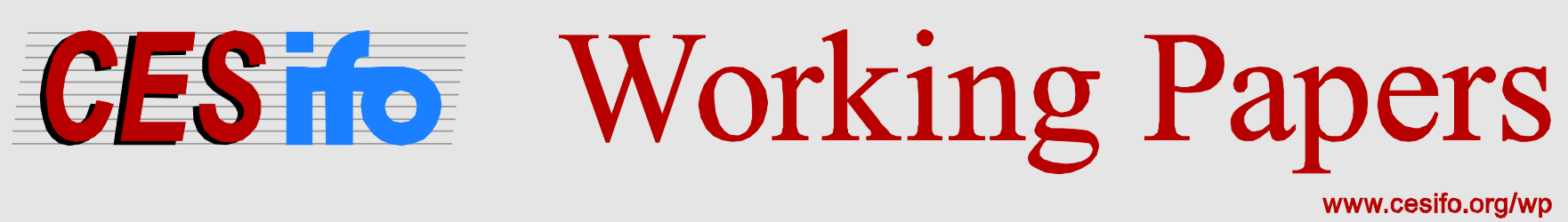

\title{
The Green Paradox in Open Economies
}

\author{
Ngo Van Long
}

\author{
CESIFO WORKING PAPER NO. 4639 \\ CATEGORY 9: RESOURCE AND ENVIRONMENT ECONOMICS \\ FEBRUARY 2014
}

An electronic version of the paper may be downloaded

- from the SSRN website:

- from the RePEc website:

- from the CESifo website:

www.SSRN.com

Www.RePEc.org

www.CESifo-group.org/wp

\section{CESifo}




\title{
The Green Paradox in Open Economies
}

\begin{abstract}
This paper explains how, in the context of incomplete coordination among all countries, unilateral policies that might at first sight seem pro-green could actually turn out to harm the global environment. The free-riding motives and the difficulty of reaching an effective international environmental agreement are reviewed. As a first step, the various channels that lead to carbon leakage in static models of open economies are identified, and some simulation results are reported. This is complemented by a review of the possibility of green paradox outcomes in dynamic open-economy models with an exhaustible resource exploited by farsighted firms. It is shown that border tax adjustments can lead to a green paradox outcome. Directions for future research are suggested.
\end{abstract}

JEL-Code: Q540, Q420, Q300.

Keywords: green paradox, climate change, carbon leakage.

Ngo Van Long

Department of Economics

McGill University

Canada-Montreal H3A 2T7

ngo.long@mcgill.ca 


\section{Introduction}

How to mitigate the climate change is one of the most important problems facing the world today. Efforts to secure cooperation by all countries have failed because of the incentive to free ride. The first best outcome is therefore not feasible. The world is thus left with an assortment of proposed policy options that at first sight might look like second best or third best measures to improve welfare relative to the "business-as-usual" (BAU) scenario. However, as often is the case, a careful analysis would reveal that some policies that seemingly would do the job could actually turn out to have an adverse effect on the environment, contrary to the good intention of the policy makers. Such outcomes are called green paradox outcomes (Sinn, 2008a,b, 2012). There is by now a large body of literature that identifies various channels by which well-intentioned environmental policies may lead to green paradox outcomes.

The main purpose of this paper is to show how green paradox outcomes may arise in a world where climate-change policies are adopted by individual countries or sub-coalitions of countries, in the absence of a grand coalition that would ideally adopt first best policy measures. We will in particular explore the contexts in which international trade and international factor movements may play a role in magnifying or attenuating the green paradox.

In the recent economic literature, the term green paradox has been used both in a broad sense and in a more narrowly defined sense. In the broad sense, any environmental policy that is formulated with the intention of improving environmental quality that turns out to have adverse consequences for the environment is called a green paradox outcome. In a more narrowly defined sense, the green paradox refers to environmental policy failure owing to the failure to recognize the intertemporal supply behavior of extractors of fossil fuel resources. According to this narrower sense, policies that affect resource demand can turn out to be counterproductive because of incorrect analysis of the supply side of the resource market, which is inherently dynamic. As Bretschger and Smulders (2012) put it, "If a policy is not well designed for resource markets it might result in worsening the conditions for sustainability, counteracting the intention of policy makers. This was recently popularized under the title of the 'green paradox' (Sinn, 2008b), but known in the literature much earlier (Long and Sinn, 1985). It may be exactly the intertemporal arbitrage conditions driving basic resource extraction which evoke this kind of market reactions undermining climate policies."

In this paper, we take the views that, as a first step, one can discuss some green paradox results without an explicit recognition of the intertemporal optimization behavior of owners of fossil resource stocks, and that ultimately a deeper understanding of the green paradox literature would require an appreciation of the theory of supply of fossil fuels firmly grounded on the microeconomics of the resource extracting industry.

Accordingly, the plan of the remaining part of this paper is as follows. In the next section, we analyse the green paradox for open economies in a static framework without an explicit analysis of the exhaustibility of fossil resources. This will be followed by a section that explicitly takes into account 
intertemporal supply behavior of resource extracting firms, where we reveal dynamic sources of green paradox outcomes in a trading world.

\section{Green Paradox in Static Models of Open Economies}

While the center piece of Sinn's analysis of the green paradox is intertemporal supply behavior of owners of stocks of fossil fuels, it is possible to construct simple examples of green paradox outcomes in a purely static framework. In an interesting model that abstracts from the time dimension, Hwang and Mai (2004) show that an increase in the pollution tax can increase the pollution damages to residents of a central business district (CBD). This is clearly a green paradox result (though the term was not invented until 2008). The model assumes that a firm's location is endogenous. Assume there is a monopolist that buys its inputs from two suppliers (e.g. two farms) located at two points on the periphery of a region and ships his output to the CBD. The monopolist's plant is located somewhere between the CBD and the location of the input suppliers. Its exact location is determined by balancing the cost of shipping inputs to the plant, and the cost of shipping output to the CBD. The pollution generated by the firm is caused by emissions from the plant. Assume that pollution is proportional to output. The pollution as measured at the center of the CBD is only a fraction of the pollution generated at the plant. This fraction is a decreasing function of the distance between the plant and the CBD. An increase in an emission tax rate will make the firm produce less output, and thus its total emissions are reduced. Suppose the production function exhibits decreasing returns to scale. Then as the firm cuts back its production, less of each input is needed per unit of output. Cost minimization (balancing input transport costs with output transport cost) then dictates that the firm moves closer to the CBD. As a result, even though total emissions fall, the pollution damages inflicted on the CBD may rise. This is a green paradox outcome. This outcome would not arise if the tax is based on pollution damages at the CBD and not on the emissions at the plant.

While the model of Hwang and Mai (2004) does not deal with open economies, by endogenizing the choice of a firm's location, it is pointing out to a root of the green paradox: policy makers quite often fail to take into account the full ability of firms or individuals to make spatial or intertemporal adjustments to their plans in response to policy measures. The literature on "carbon leakage" is based on the same insight. For example, the carbon-leakage model by Babiker (2005) assumes spatial competition among Cournot oligopolists, a feature that has been exploited in modeling firms' locational choice (Markusen and Venables, 1988, Markusen et al., 1993, 1994).

Hoel (1997) also explored the issue of endogenous plant locations between two countries, and showed that the Nash equilibrium of the environmental-policy game between two countries is generally not Pareto optimal.

Eichner and Pethig (2011) define carbon leakage as the phenomenon where "the effort of abating countries will be offset to some extent by increasing emissions in non-abating countries." The co-existence of abating countries and non-abating countries is a fact of life. The explanation of this 
phenomenon is the free riding incentive. Earlier discussions of this issue include Bohm (1993), Hoel (1992, 1994), Carraro and Siniscalco (1993), and Barrett (1994).

\section{Why don't countries cooperate?}

Barrett (1994) and others have shown that if countries decide whether to participate in an international environmental agreement (IEA) based on their own selfish interest, then even in the simple case of identical countries, very few countries will want to join an IEA. A grand coalition (i.e. a coalition in which all countries are members) will not arise unless the number of countries in the world is very small. ${ }^{1}$

Limited participation in international cooperation lies at the heart of many green paradox effects. Actions that are motivated by good intention may have bad consequences if others do not follow.

Does the possibility of trade lead to expansion of the size of a stable IEA? Eichner and Pethig (2013) show that the answer is in the affirmative, in the case where the IEA acts as a Stackelberg leader. However, the aggregate emissions turn out to be not much different from the business as usual scenario.

When countries are heterogeneous, cooperation is even more unlikely. Hoel (1992) considers the case where countries have identical cost of emission reductions, but they differ with respect to their evaluation of the benefit of the public good. Countries can elect to join an IEA. Members will vote on a uniform reduction that they must carry out. The equilibrium rate of reduction is the outcome of the median voter mechanism. Hoel showed numerically that in a world consisting of 100 countries, only 2 countries will join an IEA, and their emission reduction is very negligible.

In the IEA literature, once an IEA forms, two scenarios are possible: (a) the IEA members are assumed to act simultaneously with the other non-signatories, or (b) the IEA members are assumed to have the ability to move first and announce their emissions policies before the non-signatories choose their respective emissions policies. Both scenarios lead to the same pessimistic outcome: very few will join an IEA, and the IEA's cut in pollution will be largely offset by increasing emissions of non-members. This is an instance of "carbon leakage" even when there is no trade among countries (for example when there is only one final good and inputs are not traded internationally).

In a recent contribution, Buchholz et al. (2012) allow IEA members to make a different kind of commitment, which enables them to act as the first mover relative to non-members. In their

1 Barrett (1994) used a linear-quadratic model, with quadratic damage costs. If damage costs are linear, as was assumed in some of this literature, then non-members have a dominant strategy, and leakages do not occur. The result that participation to IEA is low may be due to the functional forms assumed. Karp and Simon (2012) use a non-parametric model and show that participation can be large. Battaglini and Hardstad (2012) find high participation in a model of multistage participation game with investment. 
formulation, members agree to a matching rule: if a member contributes a flat amount $g_{i}$ to a public good (abatement), then other members will jointly match this contribution at a rate $\rho$ so that the contribution $g_{i}$ induces $(1+\rho) g_{i}$. They find that there are parameter values that imply $\rho<0$ in equilibrium. Then if an IEA coalition is not a grand coalition, its formation will actually result in more pollution for the world. In this model, when $\rho<0$, it is the coalition that exploits the non-members. In a way, this is another green paradox result: when a first best action (here, full cooperation by all countries) is not available, actions that might resemble a second best solution (forming an IEA with a few members) may actually be worse than no action at all.

The intuition behind the result of Buchholz et al. (2012) is as follows. Emission reductions are strategic substitutes, in the sense that if one player contributes more to a public good, then other players will respond by contributing less. A subset of players can therefore gain if it can act as a first mover, declaring that it contributes less, so that others will contribute more. ${ }^{2}$ The choice of $\rho$, which is made before all players make their contributions, amounts to a commitment device by the coalition, turning it to a Stackelberg leader.

The above models rely on the non-cooperative game theory. Authors using the cooperative game theory offer a more optimistic view concerning IEA. Chandler and Tulkens (1995) use the concept of the gamma-core as solution concept for their cooperative approach to IEA. They find that the grand coalition is the equilibrium outcome, therefore the carbon leakage problem does not arise. The gammacore approach basically assumes that each member of an IEA perceives that if it leaves the coalition, then all existing members will follow suit. This is a strong deterrent against leaving. The static model of Chandler and Tulkens (1995) has been modified by Germain et al. (2003) to take into account the dynamics of pollution, and transfers among countries in a dynamic setting. In this formulation, in any period, a country may decide to join a grand coalition, or to stay outside. It is assumed that if it chooses the second alternative, then it will expect that in the following period, a grand coalition will be formed. Thus this formulation retains the basic optimism of the static model of Chandler and Tulkens (1995). ${ }^{3}$ There is no surprise then that the conclusion of the paper is that there exists a transfer scheme that supports full cooperation.

It seems that the approach typified by Barrett (1994) and that of gamma core are at two opposite extremes. The former assumes that quitting is not punished, the latter assumes that quitting is met with maximum punishment. As some critics have said, the truth lies somewhere in between.

\footnotetext{
${ }^{2}$ Long (1992) shows that this is the case even in a dynamic game: A player that can act as Stackelberg leader will contribute less than it would if it were playing the simultaneous move game.

${ }^{3}$ Martimort and Sand-Zantman (2013) develop a model in the tradition of Chandler and Tulkens (1995), where participation is high (essentially by assumption) but abatement may be low because of asymmetric information.
} 
In the formulation of Barrett's IEA game, each of $N$ countries must choose to join or not to join a coalition. An IEA among $M$ countries determines $M$ abatement levels, one for each coalition member, so as to maximize the sum of their payoffs. If $M=N$ the coalition is called the grand coalition. Barrett adopts the concept of coalitional stability originally proposed by d' Aspremont et al. (1983) for cartel stability. Under this formulation, when a country considers joining or leaving a coalition, it assumes that the rest of the countries in the coalition will maintain their membership status and will continue to cooperate, choosing their action to maximize their joint welfare. Let $\pi^{s}(M)$ and $\pi^{\text {ns }}(M)$ denote the equilibrium payoffs of signatory and non-signatory countries when the coalition has $M$ identical members. A coalition with $M$ members is said to be internally stable if no signatory would gain by leaving the coalition, i.e., if $\pi^{s}(M) \geq \pi^{n s}(M-1)$, and it is said to be externally stable if a non-signatory would not gain by joining it, i.e. $\pi^{n s}(M) \geq \pi^{s}(M+1)$. An IEA is called stable if and only if it is both internally and externally stable.

Some authors have argued that the external and internal stability criterion is based on the premise that agents are myopic. This concept of stability has been referred to by de Zeeuw (2008) as "myopic stability" since a player does not foresee any change that might occur in the coalition following its defection. A more sophisticated player would anticipate that by defecting, other players' incentives to defect might be affected. Diamantoudi and Sartsetakis (2008) and Osmani and Tol (2009) adopt the concept of a " farsighted stable IEA". This concept is borrowed from developments in coalition formation theory (Chwe,1994, Xue, 1998).

In their pioneering work on farsighted stable IEAs, Diamantoudi and Sartsetakis (2008) extended the existing literature by endogenizing the reaction of the IEA members to a deviation by a member or group of members. Thus, when a country contemplates leaving or joining an agreement, it takes into account the reactions of other countries. The authors identified conditions under which there always exists a unique set of farsighted stable IEAs. They showed that farsighted IEAs can be significantly larger than the stable IEAs under the internal external stability criterion. While a formal definition of the concept of far-sighted stability would require a lot of preliminary definitions that are heavy in mathematical symbols and set-theoretic concepts, a rough idea can be obtained by considering the case of a world consisting of four countries. Suppose countries 1,2, and 3 form an IEA. Then country 3 considers withdrawing from it. Suppose that this withdrawal would be gainful to country 3 if countries 1 and 2 would remain members of a two-country coalition. If we use the internal and external stability criterion of d'Aspremont et al. (1983), then it follows that the three-country coalition is not stable. On the contrary, under far-sighted stability, country 3 cannot presume that once it has left, countries 1 and 2 would remain in a two-country coalition. These two may well contemplate leaving the two-country coalition, because this could destroy country 3's hope of free riding, and thus inducing it to rejoin the three-country coalition. Thus a three-country coalition can be stable in the sense of far-sighted stability, though it is unstable in the sense of internal and external stability of d'Aspremont et al. (1983). Whether a three-country coalition in a four-country world is far-sightedly stable or not depends on specifications of parameters of the damage function and the production functions. Numerical examples 
of farsightedly stable three-country coalition in the four-country world can be found in Benchekroun and Ray Chaudhury (2013), where both the static pollution framework of Barrett (1994), and the dynamic pollution accumulation framework (as in Long (1992), Dockner and Long (1993), Ploeg and de Zeeuw (1992)) are considered. It is important that countries 1 and 2 make credible threats to country 3 . This issue is explained in Benchekroun and Ray Chaudhury (2013).

The above models did not consider negotiations. Hoel (1991) considered international negotiations. He reported a carbon leakage result: when a country unilaterally reduces its emissions, this will generally affect the outcome of international negotiations about emission reductions. The final outcome may well give rise to higher total emissions when one country reduces its emissions than when all countries act selfishly. This will be the case if countries restrict their negotiations to equal or proportional abatements. ${ }^{4}$

\section{Carbon leakage in a trading world: static models}

Unilateral reduction of emissions by one country or one subset of countries can lead to a problem called "carbon leakage" via reduction of fuel prices. Assuming that fuels are traded in the world market, Bohm (1993) and Felder and Rutherford (1993) were among the first authors to discuss this issue, though Bohm did not use this terminology. As Bohm points out, "such unilateral actions or international treaties among a limited number of countries would tend to reduce world-market fuel prices and, hence, increase fuel consumption in non-signatory countries" (p. 258). This consideration is later referred to as the "fuel price effect" (FPE). ${ }^{5}$ Using a static model, and taking into account both the demand side and the supply side, Bohm suggests that the carbon leakage problem through the fuel price effect could be mitigated if signatories buy or lease fossil fuel deposits from fuel exporting countries and store such oil in their original deposits. This would reduce the fossil-fuel supply to non-signatories. Harstad (2012) offers a formal model along these lines. Another channel through which carbon leakage can arise is the relocation of plants in response to emissions taxes or regulations (Markusen et al., 1993, 1995). A third channel is the change in a country's comparative advantage induced by

\footnotetext{
${ }^{4}$ For a more technical review of IEA issues, see Benchekroun and Long (2012).

${ }^{5}$ Bohm also points out another problem: many poor fuel-exporting countries could be seriously hurt, with undesirable political consequences for the world.
} 
its adoption of tougher environmental policies (Copeland and Taylor, 2003, 2004, Krishna, 2010). ${ }^{6}$

In Bohm's model, there is no trade in the final goods among countries. When there is trade in final goods, a country that unilaterally imposes an emission tax on its (fossil-fuel-using) final good industry will find that consumers will switch their expenditure to the untaxed foreign final-good substitutes. Output of these goods will therefore go up to meet the demand, creating more emissions in the non-abating countries. This "expenditure switching effect" (ESE) from taxed dirty domestic goods to untaxed dirty foreign goods tends to reinforce the carbon leakage effect found in models without trade. ${ }^{7}$

On the other hand, if the dirty good uses both carbon and a clean input (say, a composite factor $K$ ) which is an imperfect substitute for carbon, and if this clean input is internationally mobile, the pollution tax in a country may increase its demand for the clean input, so that less of this input will be available in the foreign countries. This may to some extent reduce the output of foreign goods. This is a negative leakage effect that mitigates the positive leakages mentioned above. This effect has been termed "abatement resource effect" (ARE) by Fullerton et al. (2011) and Elliott and Fullerton (2012). Negative leakage can also occur if technology adoption is endogenous. An increase in carbon tax in one country that leads to $R \& D$ in abatement can lead to adoption of the new technology in other countries or sectors (Golombek and Hoel, 2004, Gerlagh and Kuik, 2007, Di Maria and Smulders, 2004, Di Maria and van der Werf, 2008). ${ }^{8}$

\footnotetext{
${ }^{6}$ However, Chau (2003) points out that more stringent environmental policies can increase the demand for factors used in abatement. If these factors are used intensively in the clean sector, this resource-pull away from the claen good sectot can decrease the supply of the clean good and increase its relative price, creating a comparative advantage for the dirty good. Karp (2012) expands on this idea, and shows that the Copeland-Taylor-Krishna finding that higher emission tax increases the autarchic price of the dirty good depends crucially on the assumption that the production function of the dirty good is separable in capital, labor, and emissions, such that production and abatement use the same capital-labor ratio. Karp (2012) demonstrates that when this assumption is relaxed, the opposite result can occur.

${ }^{7}$ In the carbon leakage model of Ishikawa and Kiyono (2006), there is no international market for fuels. Each country produces outputs using a composite factor (say labor) and a dirty input that is freely available, except there are taxes for using this dirty input.

${ }^{8}$ Endogenous policy responses by governments of non-participating countries can mitigate the leakages when income effects are taken into account. See Copeland and Taylor (2005).
} 
The magnitude of the carbon leakage associated with a unilateral carbon tax depends on the magnitude of various parameters. Leakage increases with the consumer's elasticity of substitution between the domestic dirty goods and the foreign dirty goods, but decreases with the polluting firm's elasticity of substitution between carbon (or carbon-intensive inputs) and the clean composite input. There are of course other relevant parameters such as the degree of competition among firms, the supply elasticity of fossil fuels, and so on. Using a computable general equilibrium model, Babiker (2005) found that the leakage could be as high as $130 \%$, because of relocation of carbon-intensive industries away from rich countries that undertake stricter environmental policies. ${ }^{9}$ With relocation, unilateral action by one country leads to a green paradox outcome. Babiker's model allowed for spatial competition by Cournot oligopolists. Babiker made use of a data set based on the Global Trade Analysis Project (GTAP) data together with data from the International Energy Agency. The model, being static, does not take into account the inter-temporal supply behavior of firms in the fossil fuels sector. Exogenous assumptions are made on the price elasticity of supply for fuel.

Most CGE models however produce smaller estimates of carbon leakages. Winchester et al. (2011), using the EPPA4 model in Paltsev et al. (2005), found in their simulations of a U.S. carbon policy that the leakage would be only around 10\%. Elliot et al. (2010) found that the increase in emissions by non-Annex $B$ countries of the Kyoto Protocol relative to the emission reduction by Annex $B$ countries is within the range of $15 \%$ to $25 \%$. Burniaux and Martin (2012) emphasized that carbon leakages are small because of the assumption that the supply of coal is fairly elastic over the medium term. ${ }^{10}$

Since OECD countries are net importers of embodied emissions from non-OECD countries, it has been suggested that carbon tariffs could reduce leakage. Carbon tariffs are also known as border tax adjustments (BTA). Advocates for BTA include economists such as Stiglitz and Krugman. Keen and Kotsogiannis (2011) define BTA as differential taxation of traded goods that is motivated by differences in underlying carbon prices. In particular, they consider the

\footnotetext{
${ }^{9}$ The model employed by Babiker (2005) is based on the MIT's "Emissions Prediction and Policy Analysis" (EPPA) model described in Paltsev (2001).

${ }^{10}$ Econometric estimates by Aichele and Felbermayr (2012) found that Kyoto membership reduces carbon emissions and increases carbon imports, but does not change the level of emissions embodied in consumption and investment of members. Presumably non-members' consumption of the dirty goods may fall, so one cannot say that the leakage rate is $100 \%$. See Karp (2012) for further discussions on this point.
} 
possibility of "setting a charge on imports equal to some notion of carbon tax 'not paid' abroad, and remitting tax on exports in similar fashion." (p. 2)

Böhringer, Carbone and Rutherford (2011) simulated the effects of embodied carbon tariff. They found that carbon leakage is reduced thanks to the BTA. Similar simulation results are surveyed in Elliott and Fullerton (2012). These studies found that the main effect of BTA is to shift the burden of climate policies to less developed countries. On the other hand, Jacob et al. (2013) reported that, based on empirical data for the year 2004, full BTA applied by the European Union on imports from and exports to China would actually increase carbon leakage, because China's production would be shifted from the export sector to the non-export sector, which is more carbon intensive.

Karp (2012) uses a static partial equilibrium model to provide an example in which BTA can create negative leakage, where he defines leakage as the number of units of outsiders' increased emissions per unit of insiders' decreased emissions (p. 16). In the initial situation, there are $n$ identical countries that produce a carbon-intensive good, and there is no trade. Suppose the governments of $m$ of these countries agree to introduce a carbon tax. Then these member countries begin to import the dirty good from the non-participating countries, a leakage. Suppose the m member countries impose a BTA that sets a charge per unit import equal to the price of carbon times the carbon content of the imported good. Since the demand for the dirty good in the member countries fall (because of the carbon tax), the BTA on top of the carbon tax causes the member countries to become exporters of the dirty good. In this case, the BTA is in effect an export subsidy instead of an import tax. Karp (2012, p. 21) describes this as a negative leakage, and notes that in this case insiders lose and outsiders gains (ignoring environmental considerations). ${ }^{11}$

\section{Dynamic Multi-country Models with Inter-temporal Supply Emphasis}

About $75 \%$ of anthropogenic carbon emissions are accounted for by the burning of fossil fuels. Thus, it is imperative to take into account the behavior that governs the extraction decisions of owners of fossil-fuel deposits. Bohm (1993) was among the first to point out that climate policy

\footnotetext{
${ }^{11}$ McKibbin and Wilcoxen (2009) also find examples of negative leakages caused by BTA, using a CGE model, although the mechanism is not clear.
} 
discussions should take into account the supply side. However, he did not offer a formal model to account for the inter-temporal supply responses of sellers of fossil fuels to policy changes. Sinclair (1992) explicitly points out the need for such a model: "the key decision of those lucky enough to own oil wells is not so much how much to produce as when to extract it." Sinclair (1994) and others have studied the time path of first best carbon price under alternative specifications of damage costs. While it is true that, in a world without political constraints, the optimal price of a ton of carbon emissions at any point of time is equal to the present value of all future marginal damage costs, realistically such a policy cannot be implemented. Policy makers are likely to feel more comfortable with a gradual approach, where significant carbon taxes are delayed into the future. However, such gradualism can be counter-productive. As Sinn (2008a, p. 360) points out, if suppliers of fossil fuels "feel threatened by a gradual greening of (demand-reducing) policies in in the Kyoto countries that would damage their future prices, they will extract their stocks more rapidly, thus accelerating global warming." Sinn calls such an outcome a green paradox. Gerlagh (2011) makes a distinction between "weak green paradox" and "strong green paradox". The former refers to increases in near-term emissions, while the latter refers to increases in the present value of all future damage costs.

While there is by now a large literature on the green paradox with an inter-temporal-supplyside emphasis, almost all authors restrict attention to the case of a single country. This modeling strategy ignores an important real world element: we live in a multi-country world, with a diverse array of climate policies. It is important to know whether good-intentioned actions by one country may lead to bad outcome because of lack of actions by other countries.

\section{Carbon leakage in two-country models with a fixed resource stock to be extracted over time and a renewable substitute}

We now turn to two models of carbon leakage involving two countries, a finite stock of fossil-fuel resource to be extracted over time, and a clean, perfect substitute for fossil fuel. The first model, proposed by Hoel (2011), assumes that the perfect substitute can be produced at constant unit cost, and this technology is available to both countries. In contrast, the second model, proposed by Grafton et al. (2012), assumes that the perfect substitute is produced under increasing cost, and this technology is available to one country only. Both models deliver the result that apparently good-intentioned policies can lead to unfavorable climate outcomes.

Hoel (2011) proposes a two-country model that takes into account the fact that resource extraction involves the inter-temporal optimization by resource extracting firms. This 
model assumes that goods (including oil) flow freely between the two countries: there are no tariffs. The policy instruments available to a country are taxes on the domestic consumption of the dirty energy, and production subsidies for a perfect substitute (e.g. solar energy) that is not internationally traded. The perfect substitute is available at a constant unit cost, $b$, and this constant cost technology is available to both countries. The size of the aggregate fossil-fuel resource stock to be exhausted is exogenously given. Extraction cost is zero for simplicity. Resource owners are perfectly competitive: extractive firms do not think that they can influence the price. Oil is traded internationally, while the substitute is not tradable. In this model, it is irrelevant where the resource deposits are located. The aggregate resource stock will be exhausted at some time in the future. This time is endogenously determined. Policies can only affect the time path of extraction, not the total cumulative emissions (which are fixed, because the fossil fuel stock will be exhausted). The consumer price of oil in each country is equal to the oil producer price plus the unit carbon tax imposed by that country. When the consumer price of a country reaches the value $b$, consumers in that country will switch to the perfect substitute. Resource owners can sell oil to either market. It follows that the resource rents in the two markets are equalized, and they rise over time at an exponential rate equal to the rate of interest. The resource rent at time zero is an endogenous variable; it depends on the carbon tax rates.

Assume that country $i$ imposes a constant tax rate $\theta_{i}$ per unit of carbon consumed, where $\theta_{i}$ is smaller than $b$. Then consumers in country $i$ will switch to the clean substitute at time $T_{i}$ where $T_{i}$ satisfies the condition that the country $i$ consumers' price of oil at time $T_{i}$ just equals the price of the perfect substitute. ${ }^{12}$

Consider first the simple case where both countries have identical demand curves and impose the same carbon tax rate. Then, obviously the two switching times coincide, and if both countries increase their carbon tax rate by the same amount, the consumer's price of oil at each date will be higher, implying that less will be demanded at each point of time. Consequently the time of exhaustion of the fossil fuel stock will be delayed. This reduces the present value of total damage costs. The "green policy" is working correctly in this case.

${ }^{12} \psi_{0} \exp \left(r T_{1}\right)+\theta_{1}=b$, and $\psi_{0} \exp \left(r T_{2}\right)+\theta_{2}=b$ by Hotelling Rule, where $\psi_{0}$ is the the resource rent at time zero. This pair of conditions and the condition that the sum of the cumulative demands for oil in the two countries must equal the fixed stock of oil $X_{0}$ determine the three endogenous variables, $\psi_{0}, T_{1}$ and $T_{2}$. 
However, when countries do not coordinate their policies, a unilateral green policy in one country may not necessarily reduce the present value of total damage costs. If policy parameters are different, then in general the two switching times are different. Then a policy change that leads to a narrowing of the gap between these two switching times will lead to a green paradox outcome. To illustrate, consider the polar case where the demand for energy is completely inelastic (i.e., the demand curve is vertical). Suppose $D$ units of energy are demanded in each country per unit of time. Assume that country 1 has a higher carbon tax rate. Then consumer price in market 1 will reach the price $b$ at an earlier time than that in market 2 . Now suppose country 2 (the low tax country) increases its carbon tax rate marginally. Then the date of resource depletion will be brought closer to the present. This will increase the present value of the future damage cost, a green paradox result. ${ }^{13}$

This result can be generalized to the case of demand function that is less than completely inelastic. To summarize, if the demand for energy is sufficiently price-inelastic, the total climate costs will increase if the carbon tax is marginally increased in the country that initially has the lowest tax.

The change in world welfare is in general not the same as the change in total climate costs. This is because a carbon tax in an economy creates a distortion if the climate effects are absent. If the countries have different carbon tax rates, the marginal distortions are not equalized, which is itself a source of inefficiency. However, it remains true that if the marginal climate cost is high enough, the secondary effects of a tax change on distortions are dominated by the climate effect. Then, if the demand for energy is sufficiently price-inelastic, world

${ }^{13}$ The proof of this result is straightforward. We have two equations $D T_{1}+D T_{2}=X_{0}$, and

$$
T_{1}-T_{2}=\frac{1}{r} \ln \left[\frac{b-\theta_{1}}{b-\theta_{2}}\right]
$$

Since $\theta_{1}$ is greater than $\theta_{2}, T_{1}$ is smaller than $T_{2}$. We can see that a marginal increase in $\theta_{2}$ (such that the new $\theta_{2}$ is still lower than $\theta_{1}$ ) will decrease $T_{2}$, i.e., the exhaustion date is brought closer to the present. 
welfare will decrease if the carbon tax is marginally increased in the country that initially has the lowest tax.

Let us now turn to the analysis of the effect of technological progress. What happens if due to exogenous technical progress, the cost of the substitute falls? If the two countries are identical, the date of exhaustion will be brought closer to the present, and we obtain a weak green paradox result. ${ }^{14}$ Now consider the situation where the countries have different carbon tax rates. Let $\theta_{1}$ be greater than $\theta_{2}$, which implies that $T_{1}$ is smaller than $T_{2}$. Then a fall in $b$ may cause $T_{2}$ to increase or decrease. In the special case of completely inelastic energy demand, it can be shown that $T_{2}$ increases and $T_{1}$ decreases when $b$ falls. In this polar case, total climate costs falls if the present value of the social cost of carbon is declining over time. More generally, as long as the demand is sufficiently inelastic, a fall in $b$ can increase $T_{2}$ if $\theta_{1}$ is greater than $\theta_{2}$. The fall in $b$ then has two opposing effects on emissions (a) it reduces the resource rent, leading to lower prices, increasing early emissions (a weak green paradox), and (b) it increases $T_{2}$, leading to more emissions in the final stage, and as a consequence, because total emissions are fixed due to the assumption that the fixed stock of exhaustible resources is eventually used up, the emissions in the medium run decrease. In this case, the effect on total climate costs is ambiguous.

Finally, we consider the impacts of a subsidy on the consumption of the substitute. Assume that in country $i$ a per unit subsidy $\sigma_{i}$ is introduced and is expected to remain constant forever. ${ }^{15}$ If both countries increase the per unit subsidy by the same amount, the effect on climate costs are the same as that created by a fall in the production cost of the substitute. Consider then the case of an increase in subsidy for consumption of the renewable substitute in only one country. Suppose $\sigma_{2}$ is greater than $\sigma_{1}$ and the carbon tax rates are the same in both countries. Then $T_{1}$ is smaller than $T_{2}$. Consider a marginal increase in $\sigma_{1}$. The price of oil will fall, increasing near-term emissions in both countries, a weak green paradox result. But $T_{2}$ will increase, lengthening the life of the exhaustible resource stock. Therefore late emissions increase. It follows that medium-term emissions decrease. Assume the marginal damage cost is constant over time, which implies that the present value social cost of carbon is falling over time. Then because of the net change in emissions is non-monotone over time, it is not clear what will happen to the total costs of climate change when there is a marginal increase in $\sigma_{1}$. Let

\footnotetext{
${ }^{14}$ If the present value of the social cost of carbon is falling over time, this results in an increase of total climate costs. Concerning social welfare, the positive effect of cost reduction on welfare may well be outweighed by the negative effect of higher climate costs.

${ }^{15}$ There is of course a credibility problem here. Once the fossil fuel stock has been exhausted, the governments no longer have an incentive to subsidize the renewable energy. For simplicity, let us abstract from this problem.
} 
us turn to the effect of a marginal increase in $\sigma_{2}$. Then the resource exhaustion time $T_{2}$ will fall, and extraction increases at all time $t \leq T_{2}$. It follows that in this case the result is unambiguous: A marginal increase in the subsidy rate in the country with the lowest subsidy rate will increase total climate costs.

Can a green paradox outcome arise if the perfect substitute is available in only one country, and if the marginal production cost of the substitute increases with the output level? This question is taken up in Grafton et al. (2012), using a continuous-time infinite-horizon model. There are two countries, called North and South. Both countries need energy to produce the final consumption goods. One unit of energy is obtained from one unit of oil, or one unit of a clean substitute. Oil producers sell oil to both North and South, at the same price. In North, a clean substitute is produced at increasing marginal cost. There is an ad valorem rate of subsidy on the production of the clean energy. The clean energy cannot be exported to South. The authors ask the following question: does an increase in the ad valorem rate of subsidy bring the exhaustion date of the exhaustible resource closer to the present, thus increasing the present value of total climate costs? The model distinguishes two phases. In Phase 1, both countries use oil, and the clean energy is produced in North. In Phase 2, North relies completely on the clean energy, and South is the only user of oil. The authors show that an increase in the subsidy for clean energy in North will shorten Phase 1 and lengthen Phase 2. The effect on the exhaustion time is ambiguous. In their model, a green paradox outcome is possible if a given increase in the subsidy rate expands output when the price of energy is high by much more than when the price of energy is low. The intuition is that, in such a case, oil producers, anticipating greater competition from the clean energy sector later stages, switch more oil extractions to the earlier stages. More oil will be used earlier on rather than later on. Short term pollution increases.

\section{Carbon leakage in a three-country, two-period general equilibrium model with caps on pollution permits}

While Hoel (2011) and Grafton et al. (2012) have obtained interesting results on unilateral changes in climate policies, their models are partial equilibrium in nature: there is a numeraire good in the background, and utility is linear in that good. One may wonder to what extent this quasi-linearity is responsible for the green paradox outcome. The answer is that quasi-linearity is a simplifying assumption, not a crucial assumption. To show this, let us turn to a general equilibrium model that does not rely on this quasi-linear property.

Eichner and Pethig (2011) formulate a model that emphasizes parameters such as the intertemporal elasticity of substitution (IES). They point out that the relatively modest leakage rates reported in static models were due to the neglect of inter-temporal responses. They develop a simple two-period model. They interpret period 1 as the medium term and period 2 as the very long term. There are three countries: a fossil-fuel exporting country, called country $F$, an abating country, called country $A$, and a non-abating country, called country $N$. Let us call the fossil fuel "oil" for short. Unlike to model of Hoel (2011) and Grafton et al. (2012), there is no renewable substitute for oil. Countries $A$ and $N$ use oil to produce the consumption goods. There are no other factors of production. The abating country is 
interpreted as the coalition of countries that have made a commitment to cap their emissions. There is no capital accumulation, and no extraction cost. The stock of fossil fuels is exogenously given. ${ }^{16}$

The assumption of zero extraction cost is favorable to carbon leakage because it makes oil suppliers highly willing to shift extraction from one period to another.

In this model, governments neither play Nash nor cooperate. ${ }^{17}$ In fact, governments play no role at all in country $N$ and country $F$, and the government of country $A$ is not maximizing anything: it simply tightens an emissions cap. ${ }^{18}$

The authors simply ask: how much carbon leaks into the non-abating country when the abating country tightens its emissions cap in one of the periods. Consumers have identical preferences, represented by a utility function that displays constant elasticity of substitution between period 1 consumption and period 2 consumption. There is no uncertainty of any kind. Agents maximize intertemporal utility subject to an intertemporal budget constraint, as in the standard Arrow-Debreu general equilibrium model.

The elasticity of inter-temporal substitution (IES) is denoted by $\sigma$, which can take any positive value. As $\sigma$ tends to 1 , this utility function tends to the Cobb-Douglas function. The limiting case where $\sigma$ tends to infinity implies that consumptions in the two periods are perfect substitutes (the indifference curves are then linear). The other polar case where $\sigma$ tends to zero implies that indifference curves are Lshaped (Leontief utility function).

The authors consider the climate impact of alternative policies for country $A$ : it can tighten its period 1 cap, or its period 2 cap.

The authors state that the market rate of interest is assumed to be zero (p. 771). Upon reflection, this is actually just a normalisation: all prices used by the authors can be interpreted as present value prices. Thus an interest rate (in terms of the consumption good) can be introduced into the model. It is equal to the marginal rate of substitution of period-two consumption for period-one consumption, minus 1. (See the Appendix for technical details.) This interest rate is endogenous: it changes when policy parameters change. For example, a tightening of period-one cap on emissions would tend to result in a fall in periodone output. Fuel uses will be increased in period two, because the total stock must be exhausted over

\footnotetext{
${ }^{16}$ Berg, Kverndokk, and Rosendahl (2002) take up the case where oil explorations depend on the existence of climate treaties.

17 Due to this assumption, the authors can assert that emission taxes and quotas are equivalent. This equivalence breaks down when countries play game and exert their market power. See e.g. Kiyono and Ishikawa (2011).

18 For a survey of models where countries play dynamic emission games, see Long (2010), which draws on the theoretical tools expounded in Dockner et al. (2000).
} 
the two periods. To induce consumers to reduce period-one consumption and increase period-two consumption, the rate of interest would rise.

The authors found that if the non-abating country tightens the cap in period one (while there is no cap in period two) some carbon leakage will occur, i.e. total emissions in period 1 do not fall as much as the decrease in the cap, and the rate of leakage may exceed $100 \%$ (i.e., total emissions in period 1 rise, a green paradox outcome). ${ }^{19}$

The intuition behind this green paradox result is not hard to grasp. A tightening of period 1 cap tends to induce an increase in the interest rate to shift consumption to period 2 . The period 1 price of oil falls. This induces the non-abating country to increase its period 1 demand for oil. Thus a leakage occurs. Leakage rates in excess of $100 \%$ constitute a green paradox: the non-abating country's increased demand for oil in period 1 is greater than the reduction in the period 1 cap imposed in the abating country. This would happen if the willingness to substitute period 2 consumption for period 1 consumption is weak. In the extreme case of a Leontief utility function (i.e., zero intertemporal substitutability) a green paradox outcome is inevitable. ${ }^{20}$ Assuming there is only a cap in period 1 , the authors show that if the IES is below a threshold level, then tightening period 1 cap will lead to a green paradox outcome. This threshold level is higher (i.e. a green paradox outcome is more likely) if the absolute value of the price elasticity demand for fossil fuel is greater, or the first period world output of the final good is the smaller, or the implicit permit price in country $A$ is higher, or first period emissions of the non-abating country are higher. This result turns out to be essentially unchanged if there is also a cap in period 2.

Can a tightening of the cap in period 2 lead to more emissions in period 1 ? The authors find that this will happen if and only if the price of fossil fuel in period 1 falls in response to such a tightening. It can be shown that such a price fall cannot occur in the case of a Leontief utility function.

Our explicit treatment of interest rate in the model of Eichner and Pethig (2011) shows that the interest rate effect is a powerful channel for the green paradox. In fact, this channel has been identified in Long and Stähler (2012a). They consider a two-period general equilibrium model of a closed economy with a fixed stock of exhaustible resources and show how a permanent fall (that occurs in period 1) in

19 This is their Proposition 1. Note that tightening of period 1 cap in the abating country is equivalent to an increase in period 1 emission permits in that country. By assumption, there is no international permit market.

${ }^{20}$ It is interesting to note that both in Hoel (2011) and in Eichner and Pethig (2011), the lack of substitutability favors a green-paradox outcome. However there are important differences here. In Hoel (2011), an increase in the carbon tax of the low tax country results in a green-paradox. In contrast, in Eichner and Pethig (2011), it is the tightening of the cap in the more environmentally conscious country that results in a green paradox. The two models are quite different. Hoel (2011) relies on the assumption of constant cost of producing the perfect substitute. 
the cost of a substitute in both periods generates inter-temporal reallocation of consumption in favor of period 2, where the share of the substitute in the energy sector is large. (They assume that oil extraction in period two is more costly than in period 1 because of the depletion effect.) This reallocation of consumption may require an increase in the interest rate. The rise in the rate of interest tends to shift resource extraction toward period 1 , thus increasing damages in period 1 , and possibly increasing the present-value of the stream of damages. This is a green paradox outcome. Long and Stähler (2012a) support their theoretical results with numerical simulations.

The interest rate channel suggests a possible green paradox that could arise from a Green New Deal. ${ }^{21}$ Suppose the governments of the world embark on a program of substantial public borrowing to finance colossal R\&D projects in alternative energy. This can raise the interest rate, bringing the bulk of extraction closer to the present, worsening short-term pollution.

\section{Green paradox under border-tax adjustments with dynamic supply responses}

The dynamic models surveyed above do not take into account the possible use of border tax adjustment as an additional policy instrument available to a country that imposes a tax on domestic carbon emissions. Long and Stähler (2012b) take up this issue. They modify the closed-economy model of Long and Stähler (2012b) and propose a two-period, two-country model where the equilibrium interest rate is endogenously determined in the world market, allowing for borrowing and lending between countries, as well as trade flows in oil and final goods. They show that, under certain conditions, border tax adjustments that are introduced in period 1, to be applied for both periods, can raise the interest rate and consequently increase fossil fuels extraction in period 1 and reduce fossil fuels extraction in period 2, a weak green paradox result. If the BTA is introduced in the second period, the standard green paradox follows through the announcement effect. What is interesting in their paper is that the BTA is introduced in the first period, and the green paradox is generated through the interest rate channel.

In their model, a composite good is produced using energy and capital. Energy can be obtained from fossil fuels or from a perfect substitute that is produced under constant cost, using the composite good. The fossil fuels are available only in the less developed country (called the foreign country, or $F$ ), and must be extracted using capital. Marginal extraction cost in period $t$ increases with period $t$ extraction. Furthermore, a higher extraction level in period 1 shifts the period 2 marginal extraction cost curve upwards. The perfect substitute can be produced in both the home country $(H)$ and the foreign country. The authors first consider an integrated world equilibrium, and demonstrate a weak green paradox result: they show that a technological improvement in the production of the perfect substitute

${ }^{21}$ I thank a referee for suggesting both the term Green New Deal, and the paradox of the Green New Deal. 
can have two effects: it lowers the price of fossil fuels and raises the interest rate. ${ }^{22}$ This rise in interest rate results in more extraction in period 1.

Next, they consider trade. In the laissez-faire scenario, fossil fuels are exported from $F$ to $H . \ln H$, firms that use fossil fuels are called "brown firms", and those that use the perfect substitute are called "green firms." Firms are indifferent between being brown and being green. Now, suppose the government of $H$ introduces a carbon tax that must be paid by domestic firms that use fossil fuels. In this model, such a tax by itself has no effect on world production and consumption: the brown domestic firms simply re-locate themselves to $F$. Therefore, in this setting, the carbon tax (on production) has no impact on prices of goods and of factors of production. In particular, the price of fossil fuels remains the same as in the business-as-usual scenario. Extraction levels are not affected.

Let $H$ introduce border tax adjustments, such that brown capitalists who repatriate their dividends to $H$ must pay a tax that reflects the carbon content of their repatriated dividends. This is effectively a carbon tax on consumption. This tax is designed so that in $H$ the consumer price of the brown consumption good is equal to that of the green consumption good. As a result, the price of the brown consumption good in $F$ falls by the amount of the tax. This induces a fall in the price of fossil fuels, to the advantage of $H$. This fall has a similar impact on the interest rate as the technological improvement that lowers the price of fossil fuels in the close-economy model of Long and Stähler (2012b): the rate of interest may rise, to shift consumption toward the future. If the increase in the rate of interest is large enough, extraction will be shifted to period 1 , which is a weak green paradox result.

\section{Concluding Remarks}

We reviewed the various channels that can give rise to green paradox outcome in a world where countries do not coordinate their environmental policies. We found that in static frameworks, carbon leakage can arise, and the leakage rate may exceed $100 \%$, even though most static simulations revealed much lower leakage rates. The static models however ignore dynamic supply responses by owners of fossil fuel stocks, and the estimated leakage rates may display a downward bias. In dynamic models, two more channels are identified. First, extractions can be shifted from the future to the present, even if the interest rate is constant. This can happen when countries adopt different levels of carbon tax. Second, the rate of interest rate can change when the tax rates change. This favors more current extraction. The dynamic models however tend to be very simple in structure because the Ockham's razor principle has been used. Many real world complexities have been left out in order to focus on the main mechanisms behind the green paradox in a world with heterogeneous countries.

\footnotetext{
${ }^{22}$ The increase in the interest rate is a consequence of a wealth effect. The world as a whole becomes wealthier because of the technological improvement, which has greater impact in period 2 because share of oil in the energy sector is smaller in period 2 than in period 1. For a numerical example of the increase in interest rate in response to a permanent technological improvement, see Long and Stähler (2012a).
} 
What lessons do we learn from the carbon leakage literature? First, if a large part of the world chooses to free ride, unilateral efforts to reduce domestic emissions can be ineffectual. Second, the wide range of estimates of carbon leakages obtained from a variety of static CGE models suggests that climate policy making not only suffers from uncertainty about climate sensitivity, but also from uncertainty about production structure and market responses. Third, while dynamic formulation is essential to capture the inter-temporal supply responses of owners of fossil fuel resources, the existing dynamic models of world trade with exhaustible resources are in a very early stage of development.

The main challenge is to construct dynamic computable general equilibrium models with both trade and resource extractions by forward looking agents in order to provide better estimates of the extent of carbon leakages and to guide policies. Also, other real world features such as imperfect substitutability between fossil fuels and clean energy should be taken into account. ${ }^{23}$

APPENDIX: Introducing the interest rate into the model of Eichner and Pethig (2011).

The (present-value) price of the consumption good in period $t$ is $p_{x t}$, and it is assumed that $p_{x 1}$ is unity. The (present-value) price of fossil fuel in period $t$ is denoted by $p_{e t}$. Let us denote the consumption rate of interest by $r$ such that $1+r=1 / p_{x 2}$. Then a fall in $p_{x 2}$ is interpreted as a rise in the rate of interest $r$. Let us define the price of oil in period $t$ in terms of period $t$ consumption good as follows:

$q_{e t}=p_{e t} / p_{x t}$

The Hotelling rule requires that the oil price rises at the rate of interest,

$q_{e 2}=(1+r) q_{e 1}$

This equation is equivalent to the constancy of the present-value price of oil. The oil exporting country, country $F$, is indifferent as to how much oil is produced in period 1 and period 2, as long as the sum of production equals to the total oil stock.

\section{References}

\footnotetext{
${ }^{23}$ For a model with imperfect substitution, see Long (2012). Fischer and Salant (2012) have simulated green paradox results in a dynamic model with partial equilibrium features. Another aspect that we did not cover is the heterogeneity of resource intensities, see Pittel and Bretschger (2011).
} 
Aichelle, R., and G. Felbermayer (2012), Kyoto and the Carbon Content of Trade, Journal of Environmental Economics and Management, Vol. 63, pp. 336-354.

Babiker, M. H. (2005), "Climate Change Policy, Market Structure, and Carbon Leakage," Journal of International Economics, 65(2): 421-445.

Barrett, S. (1994), Self-enforcing international environmental agreements, Oxford Economic Papers, 46, 878-94.

Battaglini, M. and B. Hardstad (2012), Participation and duration of environmental agreements, NBER Working Papers 18585, National Bureau of Economic Research, Cambridge, MA.

Benchekroun, H. and A. Ray Chaudhury (2013) Clean technology and the stability of international environmental agreements, Journal of Public Economic Theory, forthcoming.

Berg, E., S. Kverndokk, and K. E. Rosendahl (2002), "Oil Exploration under Climate Treaties," Journal of Environmental Economics and Management, 44(3), 493-516.

Bohm, P. (1993), "Incomplete International Cooperation to Reduce $\mathrm{CO}_{2}$ emissions: Alternative Policies," Journal of Environmental Economics and Management 24: 258-71.

Böhringer, C., J. C. Carbone, and T.F. Rutherford (2011), "Embodied Carbon Tariffs," NBER working paper no.17376.

Bretschger, L. and S. Smulders (2012), "Challenges for a Sustainable Resource Use: Uncertainty, Trade, and Climate Policies", Journal of Environmental Economics and Management, Vol. 64(3), pp. 279-287.

Buchholz, W., R. Cornes, and D. Rubbelke (2012), "Potentially Harmful International Cooperation on Global Public Good Provision", CESifo Working Paper No. 3891.

Burniaux, J. M. and J. O. Martins (2012), "Carbon Leakages: A General Equilibrium View," Economic Theory, Vol. 49, pp. 473-495.

Carraro, C. (1999) The Structure of International Environmental Agreements, in Carraro, C. (ed.), International Environmental Agreements on Climate Change (Kluwer Academic Publisher, Dordrecht) 9-25.

Carraro, C. and F. Moriconi (1998), International Games on Climate Change Control, FEEM Working Paper 56.98.

Carraro, C. and Siniscalco, D. (1993), Strategies for the international protection of the environment, Journal of Public Economics, 52, 309--28. 
Carraro, C. and D. Siniscalco (1997), International Environmental Negotiations, Strategic Policy Issues. E. Elgar, Cheltenham, UK, 71--96.

Chandler, P. and H. Tulkens (1995), "A Core Theoretic Solution for the Design of Cooperative Agreements on Transfrontier Pollution," International Tax and Public Finance 2: 279-293.

Chandler, P. and H. Tulkens (1997), "The Core of an Economy with Multilateral Environmental Externalities," International Journal of Game Theory 26: 379-401.

Chandler, P. and H. Tulkens (2006), " Cooperation, Stability and Self-Enforcement in International Environmental Agreements: A Conceptual Discussion," CORE Discussion Paper 2006003. Uinversite catholique de Louvain.

Chau, S. (2003), Does tighter environmental policy lead to a comparative advantage in the less polluting goods? Oxford Economic Papers, Vol. 55, pp. 25-35.

Chwe, M. (1994), "Farsighted Coalition Stability," Journal of Economic Theory, 63, 296-325.

Copeland, B. and M. S. Taylor (2003), Trade and the Environment: Theory and Evidence. Princeton University Press, Princeton, N.J.

Copeland, B. and M. S. Taylor (2004), Trade, growth, and the environment, Journal of Economic Literature, XLI(1), pp. 7-71.

Copeland, B. and M. S. Taylor, (2005), "Free Trade and Global Warming: A Trade Theory View of the Kyoto Protocol," Journal of Environmental Economics and Management 49: 205-234.

D'Aspremont, C.A., Jacquemin, J., Gabszeweiz, J., and Weymark, J. A. (1983) On the stability of collusive price leadership, Canadian Journal of Economics, 16, 17--25.

de Zeeuw., A. J. (2008) Dynamic Effects on the Stability of International Environmental Agreements, Journal of Environmental Economics and Management, 55, 163--174.

Di Maria, C., S. Smulders, and E. van der Werf (2008), " Absolute Abundance and Relative Scarcity: Announced Policy, Resource Extraction, and Carbon Emissions," FEEM Working Papers, 92.2008.

Di Maria, C., and S. Smulders (2004), " Trade Pessimists vs Technology Optimists: Induced Technical Change and Pollution Havens," Advances in Economic Analysis and Policy 4(2): article 7.

Di Maria, C., and E. van der Werf (2008),"Carbon Leakage Revisited: Climate Policy and Directed Technical Change," Environmental and Resource Economics, 39(2): 55-74.

Diamantoudi, E. and E. S. Sartzetakis, (2002, revised 2008), "International Environmental Agreements: The Role of Foresight," Working Paper. 
Diamantoudi, E. and Sartzetakis, E. S. (2007) Stable international environmental agreements: an analytical approach, Journal of Public Economic Theory.

Dockner, E., S. Jorgensen, N.V. Long, and G. Sorger (2000): Differential Games in Economics and Management Science, Cambridge University Press, Cambridge.

Elliott, J., I. Foster, S. Kortum, T. Munson, F. P. Cervantes, and D. Weisbach (2010), " Trade and Carbon Taxes," American Economic Review, May, 100(2): 465-469.

Elliott, J. and D. Fullerton (2012), "Can a Unilateral Carbon Tax Reduce Emissions Elsewhere?" Paper presented at CESifo Area Conference on Energy and Climate Economics, 9-10 November 2012, Munich.

Eichner, T. and R. Pethig (2011), Carbon Leakage, the Green Paradox and Perfect Future Markets," International Economic Review, Vol. 52, pp. 767-805.

Eichner, T. and R. Pethig (2013), Self-enforcing environmental agreements and international trade, CESifo workin paper No. 4125, CESifo, Munich.

Fischer, C. and S. Salant (2012), Alternative Climate Policies and Intertemporal Emissions Leakages, RFF Discussion Paper DP 12-16, Resources for the Future, Washington, D.C.

Fullerton, D., Karney, D., Baylis, K. (2011), Negative Leakage, NBER Working Paper No. 17001, Cambridge, MA.

Gerlagh , R. and and O. Kuik (2007), "Carbon Leakage with International Spillovers," FEEM Paper 33.2007, Milan, (http//www.feem.it)

Gerlagh , R. and M. Liski (2008), " Strategic Oil Dependence," FEEM Working Paper 72.2008.

Gerlagh, R. (2011), "Too Much Oil," CESifo Economic Studies, 57(10),79-102.

Germain, M., Ph. Toint, H. Tulkens and A. J. de Zeeuw (2003), "Transfers to Sustain Dynamic CoreTheoretic Cooperation in International Stock Pollutant Control," Journal of Economic Dynamics and Control, 28(1): 79-99.

Golombek R. and M. Hoel (2004), "Unilateral Emission Reductions and Cross-country Technology Spillovers," Advances in Economic Analysis and Policy 4(2): Article 3.

Grafton, Q., Kompas, T., and N. V. Long (2012), Substitution between biofuels and fossil fuels: is there a Green Paradox? Journal of Environmental Economics and Management, Vol. 64(3), pp. 328-341.

Harstad, B. (2012), "Buy Coal! A Case for Supply Side Environmental Policy", Journal of Political Economy, Vol. 120 (1), pp. 77-115. 
Heal, G. M. (1976), "The Relationship between Price and Extraction Cost for a Resource with a Backstop Technology," The Bell Journal of Economics, 7(2): 371-378.

Heal, G.M. (1985), " Interaction between Economy and Climate: A Framework for Policy Design under Uncertainty," in V. Smith and A. White (eds.), Advances in Applied Microeconomics, JAI Press, pp. 151-168.

Hoel, M. (1978), "Resource Extraction, Substitute Production, and Monopoly," Journal of Economic Theory 19, 28-77.

Hoel, M. (1983), "Monopoly Resource Extractions under the Presence of Predetermined Substitute Production," Journal of Economic Theory 30, 201-212.

Hoel, M. (1991),"Global Environmental Problems: The Effects of Unilateral Actions taken by one country,"Journal of Environmental Economics and Management 20:55-70.

Hoel, M. (1992) International environmental conventions: the case of uniform reductions of emissions, Environmental and Resource Economics, 2, 141--59.

Hoel, M. (1994), "Efficient Climate Policy in the Presence of Free Riders," Journal of Environmental Economics and Management 27(3): 259-274.

Hoel, M. (1997), "Environmental Policy with Endogenous Plant Locations", Scandinavian Journal of Economics, 99(2): 241-259.

Hoel, M. (2008), "Bush Meets Hotelling: Effects of Improved Renewable Energy Technology on Greenhouse Gas Emissions", CESifo Working Paper No. 2492.

Hoel, M. (2010), "Climate Change and Carbon Tax Expectations," CESifo Working Paper no. 2966.

Hoel, M. (2011a), "The Green Paradox and Greenhouse Gas Reducing Investment", International Review of Environmental and Resource Economics, 20: 55-70.

Hoel, M. (2011b), "The Supply Side of $\mathrm{CO}_{2}$ with Country Heterogeneity," Scandinavian Journal of Economics, 113(4):846-865.

Hoel, M. and S. Kverndokk, (1996), "Depletion of Fossil Fuels and the Impacts of Global Warming," Resource and Energy Economics, 18(2), 115-136.

Hwang, H, and C.C. Mai (2005), "The Effects of Pollution Taxes on Urban Areas with Endogenous Plant Location," Environmental \& Resource Economics 29: 57-65.

Ishikawa, J. and K. Kiyono (2006), Greenhouse-gas emission controls in an open economy, International Economic Review, 47(2): 431-50. 
Jacob, M., Marschinski, and M. Huebler (2013), Between a hard rock and a hard place: a trade-theory analysis of leakage under production- and consumption-based policies, Environmental and Resources Economics, Vol. 56(1), pp. 47-72.

Karp, L. (2011), The environment and trade, Annual Review of Resource Economics, Vol. 3, pp. 397-417.

Karp, L. (2012), Carbon leakage in general and partial equilibrium, Working Paper, Department of Agricultural and Resource Economics, University of California, Berkeley.

Karp, L. and L. Simon (2012), Participation games and international environmental agreements: a nonparametric model, CUDARE Working Paper Series 1128, University of California at Berkeley, Department of Agricultural and Resource Economics.

Keen, M. and C. Kotsogiannis (2011), Coordinating climate and trade policies: Pareto efficiency and the role of border tax adjustments, CESifo Working Paper No.3494.

Kiyono, K. and J. Ishikawa (2011), "Environmental Management Policy under International Carbon Leakage," Typescript, Hitotsubashi University.

Krishna, K. (2010), Limiting emissions and trade: some basic ideas, Working Paper, Pennsylvania State University.

Long, N. V., (1992), "Pollution Control: A Differential Game Approach," Annals of Operations Research, 37, pp. 283-296.

Long, N.V. (2010) A Survey of Dynamic Games in Economics, World Scientific, 2010.

Long, N. V. (2012),"The Green Paradox under Imperfect Substitutability between Clean and Dirty Fuels", paper presented at the CESifo Venice Summer Institute The Theory and Empirics of The Green Paradox, Venice, July 2012.

Long, N. V. and H.-W. Sinn (1985), "Surprise Price Shift, Tax Changes and the Supply Behaviour of Resource Extracting Firms", Australian Economic Papers, 24(45): 278-289.

Long, N.V. and F. Stähler (2012a), "Resource Extraction and Backstop Technologies in General Equilibrium", paper presented at the CESifo Venice Summer Institute The Theory and Empirics of The Green Paradox, Venice, July 2012, to appear as Chapter 5 in Pittel, K., Ploeg, F. van der, and Withagen, C. (Eds.), Climate Policy and Exhaustible Resources- The Green Paradox and Beyond, MIT Press, forthcoming.

Long, N.V. and F. Stähler (2012b), "Climate Change, Border Tax Adjustments, and the Green Paradox," paper presented at the CESifo Conference on Energy and Climate Change, Munich, November 2012. 
Markusen, J. and A. Venables (1988), "Trade Policy with Increasing Returns and Imperfect Competition: Contradictory Results from Competing Assumptions," Journal of International Economics 24: 299-316.

Markusen, J., E. Morey, and N. Olewiler (1993), "Environmental Policy when Market Structure and Plant Location are Endogenous," Journal of Environmental Economics and Management 24: 299-316.

Markusen, J., E. Morey, and N. Olewiler (1995), "Competition in Regional Environmental Policies when Plant Location are Endogenous," Journal of Public Economics 56: 55-77.

Martimort, D. and W. Sand-Zantman (2013), Solving the global warming problem: beyond markets, simple mechanism may help, Canadian Journal of Economics, Vol. 46(2), pp. 361-378.

McKibbin, W. J. and P. J. Wilcoxen (2009), The economic and environmental effects of border tax adjustments for climate policy, Lowy Institute for International Policy, Working Paper in International Economics.

Osmani, D. and R. Tol (2009), "Toward farsightedly stable international agreements", Journal of Public Economic Theory, 11 (3), 2009, pp. 455--492.

Paltsev, S., J. Reilly, H. D. Jacoby, R.S. Eckaus, J. McFarland, M. Sarofim, M. Asadooria, and M. Babiker (2005), " The MIT Emissions Prediction and Policy Analysis (EPPA) Model: Version 4, MIT JPSPGC, Report No. 125.

Pittel, K. and L. Bretschger (2011), The implications of heterogeneous resource intensities on technical change and growth, Canadian Journal of Economics, 43(4), 1173-97.

Ploeg, F. van der, and A. J. de Zeeuw, (1992), "International Aspects of Pollution Control," Environmental and Resource Economics 2: 117-139.

Ploeg, F. van der, and C. Withagen (2012), "Is There Really a Green Paradox?" forthcoming in JEEM. Oxcarre Research Paper 35, University of Oxford, Oxford, U.K.

Sinclair, P.J.N. (1992), "High Does Nothing and Rising is Worse: Carbon Taxes Should Keep Falling to Cut Harmful Emissions", Manchester School 60: 41-52.

Sinclair, P.J.N. (1994), "On the Optimal Trend of Fossil Fuel Taxation," Oxford Economic Papers 46: 869877.

Sinn, H.-W. (2008a), "Public Policies against Global Warming: A Supply-Side Approach", International Tax and Public Finance, 15(4):360-394.

Sinn, H.-W. (2008b), Das Grüne Paradoxon: Plädoyer für eine illusionsfreie Klimatpolitik, Econ Verlag, Berlin.

Sinn, H.-W. (2012), The Green Paradox, MIT Press. 
Strand, J. (2007), "Technology Treaties and Fossil Fuels Extraction," The Energy Journal 28: 129-142.

Tahvonen, O. (1997), "Fossil Fuels, Stock Externalities, and Backstop Technology," Canadian Journal of Economics, 30(4), 855-874.

Ulph, A. and D. Ulph (1994), "The Optimal Time Path of a Carbon Tax", Oxford Economic Papers 46: 857868.

Van der Werf, E., and Di Maria, C., (2011), Understanding Detrimental Effects of Environmental Policy: The Green Paradox and Beyond. CESifo Working Paper No. 3466.

Welsch, H. and F. Stähler (1990), On Externalities Related to the Use of Exhaustible Resources, Journal of Economics 51, 177-195.

Winchester et al. (2011), N. S. Paltsev and J.M. Reilly (2011), "Will Border Carbon Adjustments Work?" The B.E. Journal of Economic Analysis and Policy 11(1), Topics, Article 7.

Winter, R. A. (2011), "Innovations and the Dynamics of Global Warming," Working Paper, Sauder School of Business, University of British Columbia.

Xue, L. (1998),"Coalitional stability under perfect foresight,", Journal of Economic Theory 11, 603--627. 
